\title{
Breaking the 1000-gene barrier for Mimivirus using ultra-deep genome and transcriptome sequencing
}

\author{
Matthieu Legendre ${ }^{1 *}$, Sébastien Santini ${ }^{1}$, Alain Rico ${ }^{2}$, Chantal Abergel $^{1}$, Jean-Michel Claverie ${ }^{1}$
}

\begin{abstract}
Background: Mimivirus, a giant dsDNA virus infecting Acanthamoeba, is the prototype of the mimiviridae family, the latest addition to the family of the nucleocytoplasmic large DNA viruses (NCLDVs). Its 1.2 Mb-genome was initially predicted to encode 917 genes. A subsequent RNA-Seq analysis precisely mapped many transcript boundaries and identified 75 new genes.

Findings: We now report a much deeper analysis using the SOLiDTM technology combining RNA-Seq of the Mimivirus transcriptome during the infectious cycle (202.4 Million reads), and a complete genome re-sequencing (45.3 Million reads). This study corrected the genome sequence and identified several single nucleotide polymorphisms. Our results also provided clear evidence of previously overlooked transcription units, including an important RNA polymerase subunit distantly related to Euryarchea homologues. The total Mimivirus gene count is now $1018,11 \%$ greater than the original annotation.

Conclusions: This study highlights the huge progress brought about by ultra-deep sequencing for the comprehensive annotation of virus genomes, opening the door to a complete one-nucleotide resolution level description of their transcriptional activity, and to the realistic modeling of the viral genome expression at the ultimate molecular level. This work also illustrates the need to go beyond bioinformatics-only approaches for the annotation of short protein and non-coding genes in viral genomes.
\end{abstract}

\section{Findings}

Mimivirus, a nucleocytoplasmic large double stranded DNA virus infecting Acanthamoeba species, is the largest virus identified to date. Its icosahedral fibrillated capsid has a diameter of $750 \mathrm{~nm}$. Besides its outstanding particle size, the genome of Mimivirus is also exceptional both in size and complexity. The initial sequencing revealed a linear genome of 1,181,404 nt (roughly the size of the spirochaete bacterium Treponema pallidum genome) harboring 911 protein coding genes and 6 tRNAs [1]. Some of these genes were observed for the first time in a virus, the most salient being those involved in protein translation and DNA repair. These unique features reawaked conceptual discussions on the

\footnotetext{
* Correspondence: matthieu.legendre@igs.cnrs-mrs.fr

${ }^{1}$ Structural \& genomic Information Laboratory (CNRS, UPR2589), Mediterranean Institute of Microbiology, Aix-Marseille Université, 163 Avenue de Luminy, Case 934, FR-13288 Marseille, France

Full list of author information is available at the end of the article
}

nature of viruses and the frontier between viruses and cellular organisms [2-4].

We recently reported the first RNA-Seq study of a large DNA virus using the 454-Flex technology [5]. The transcriptome analysis of Mimivirus during its infection cycle modified the initial gene map in various aspects. First the exact mapping of polyadenylated transcripts allowed the precise location of untranslated regions (UTRs) and intron-exon boundaries. Comparison of the RNA-Seq reads to the reference genome also corrected some phase-shifting sequencing errors causing a few ORFs to be merged. In the meantime 75 new genes were revealed by their transcripts, among which 26 noncoding RNA genes that could not be identified by ORFbased gene-finding approaches. Such transcriptome analyses using massively parallel pyrosequencing nicely complemented $a b$ initio bioinformatic annotations. However, one limitation inherent to the RNA-seq approach is that sequence reads are unevenly distributed
C Biomed Central

(c) 2011 Legendre et al; licensee BioMed Central Ltd. This is an Open Access article distributed under the terms of the Creative Commons Attribution License (http://creativecommons.org/licenses/by/2.0), which permits unrestricted use, distribution, and reproduction in any medium, provided the original work is properly cited. 
along the genome. Genomic positions located in weakly expressed genes and intergenic regions exhibit a lower coverage and are thus less likely to be corrected.

To circumvent these limitations, while keeping the power of RNA-Seq for gene discovery, we performed a comprehensive re-sequencing and thorough reannotation of the Mimivirus genome using two larger and complementary data sets: an ultra-deep sequencing of genomic DNA and total RNA, both from the SOLiD ${ }^{\mathrm{TM}}$ platform. The total number of generated 50-bp reads was about 50 million for the genomic DNA dataset and 200 million for the total RNA dataset. This huge amount of new data allowed us to i) further improve the quality of the Mimivirus genome sequence, ii) identify polymorphic genomic positions (SNPs), and iii) discover previously overlooked genes, one of which encodes an RNA polymerase II subunit, increasing the Mimivirus gene count to 1018.

\section{A new Mimivirus reference genome sequence}

The Mimivirus genomic DNA library was constructed using $4.7 \mu \mathrm{g}$ of input DNA with the SOLiD ${ }^{\mathrm{TM}}$ Fragment Library Construction kit (standard protocol). After emulsion PCR the monoclonal beads were loaded on one fourth of a slide of a SOLiD ${ }^{\mathrm{TM}} 3$ Plus System and sequenced (50-base pair reads) with the $\mathrm{SOLiD}^{\mathrm{TM}} \mathrm{Opti}$ Fragment Library Sequencing chemistry. This raw sequence dataset $(45,275,001$ genomic reads), was used to build iteratively improved versions of the Mimivirus genome sequence, using the following bioinformatic pipeline (Figure 1): Starting from the original genome sequence (RefSeq ID NC_006450) as template, we first mapped the reads onto it using the Bfast program [6] in the color space with default parameters for match, localalign and postprocess subroutines. To avoid overweighting of some genomic positions caused by inhomogeneous PCR amplifications, we removed duplicated reads with the MarkDuplicate subroutine (Picard program suite: http://picard.sourceforge.net). To improve the baseresolution consensus, a micro re-alignment was performed on each read with the SRMA program [7]. With this stringent selection we only used the best representatives ( 4 to $5 \%$ ) of the initial dataset. The mapped dataset was then searched for variants (substitutions or indels) using the Samtools [8] and VarScan programs [9]. A substitution was called a change from the (current) reference genome when represented in more than $70 \%$ of the aligned reads. Indels were also validated when represented in more than $60 \%$ of the aligned reads. The validated variations were then incorporated into a new version of the genome sequence that became the new reference for the next round of corrections. The procedure was iteratively applied to convergence, i.e. until no more indels or substitutions were validated, for a total of
14 cycles. The final 1,181,549 nucleotides-long genome sequence resulting from the above corrections is now the reference Mimivirus genome sequence (RefSeq ID NC_014649). It differs by 196 substitutions, 29 deletions and 174 insertions from the original genome sequence (RefSeq ID NC_006450).

\section{Identification of single nucleotide polymorphisms}

Next-generation sequencing platforms are now providing deep enough data to readily identify single nucleotide polymorphisms (SNPs). While using SOLiD ${ }^{\mathrm{TM}}$ reads in the course of the above correction procedure, we observed a number of polymorphic positions that could not be interpreted as sequencing errors given their high frequency of occurrence. SNPs in the Mimivirus genome were then systematically pinpointed as follows: we recorded all the positions with a nucleotide differing from the reference genome sequence in more than $10 \%$ of the aligned reads and seen at least once on both strands. In addition, we excluded all the variant positions less than $25 \mathrm{nt}$ apart as they could correspond to mapping errors. The same procedure was independently applied to extract the polymorphic positions showing in $10 \%$ or more of the reads within the SOLiD ${ }^{\mathrm{TM}}$ RNA-seq dataset described hereafter. We then took the intersection of these two independent analyses to confidently identify 27 SNPs in the Mimivirus genome (see Table 1).

The number of synonymous substitutions ( 3 out of 24 coding SNPs) is surprisingly low compared to nonsynonymous substitutions. Although paradoxical at first glance such a high proportion of non-synonymous substitutions was already noticed when comparing closely related bacterial strains exhibiting a small number of mutations [10]. This is usually explained by the fact that those mutations are not deleterious enough to be rapidly eliminated from the population, i.e. the observed variations are not yet fixed. Accordingly, the observed distribution of non-synonymous vs. synonymous variations is not significantly different from what is expected by chance from the relative frequency of the non-synonymous (79\%) vs. synonymous substitutions (21\%) computed from the Mimivirus genome codon composition (Fisher exact test $\mathrm{p}[3,21 ; 5,19]>0.7)[11]$. To our knowledge this is the first genome-wide SNPs analysis of a large DNA virus. It remains to be determined whether the observed polymorphisms are representative of the true Mimivirus population diversity.

\section{Mimivirus genome harbors 1018 genes}

In addition to correcting the genome sequence we sought to thoroughly revise the Mimivirus gene annotation (Figure 1). We first identified the open reading frames (ORFs) using the "self-training" option of the Genemark ${ }^{\mathrm{TM}}$ program suite [12]. Beyond ORF annotation we delineated 


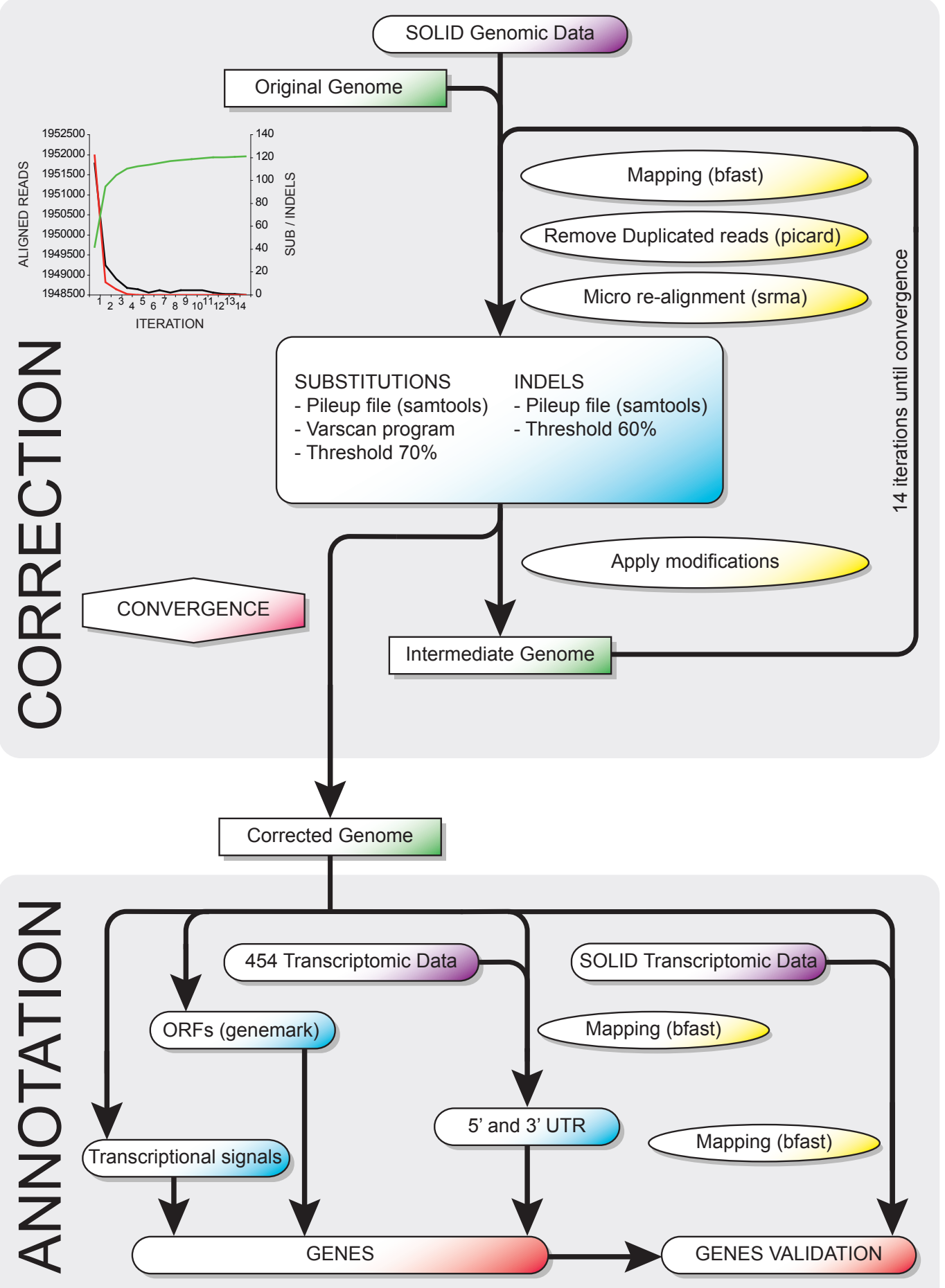

Figure 1 Flow chart of the Mimivirus genome correction pipeline. The upper panel illustrates the correction procedure and the lower panel the annotation method. Colors are used for clarity: datasets are in purple, genomes are in green, sequence manipulations (mapping, duplicate removal, or modifications) are in yellow, computation steps are in blue and genes in red. The upper left graph represents the decrease in substitutions (in red) and indels (in black) identified during the iterative genome correction process, together with the increase in the total number of reads (in green) mapped to genome. 
Table 1

\begin{tabular}{|c|c|c|c|c|c|c|c|c|c|}
\hline $\begin{array}{l}\text { Genomic } \\
\text { position }\end{array}$ & Gene & Gene annotation & $\begin{array}{l}\text { Codon (SNP } \\
\text { position in } \\
\text { bold) }\end{array}$ & $\begin{array}{l}\text { Reference } \\
\text { allele }\end{array}$ & $\begin{array}{c}\text { Reference } \\
\text { allele } \\
\text { coverage (\%) }\end{array}$ & $\begin{array}{l}\text { Second } \\
\text { allele }\end{array}$ & $\begin{array}{c}\text { Second } \\
\text { allele } \\
\text { coverage (\%) }\end{array}$ & $\begin{array}{c}\text { Reference } \\
\text { encoded } \\
\text { AA }\end{array}$ & $\begin{array}{c}\text { Second } \\
\text { allele } \\
\text { encoded AA }\end{array}$ \\
\hline 2746 & L1C & $\begin{array}{l}\text { Uncharacterized probable } \\
\text { non-coding RNA gene }\end{array}$ & - & C & 86.6 & $\mathrm{~T}$ & 13.4 & - & - \\
\hline 5402 & L3 & Uncharacterized protein & GAA & G & 78.0 & A & 22.0 & $\mathrm{E}$ & K \\
\hline 9911 & L6 & Uncharacterized protein & GTA & A & 74.2 & G & 25.8 & v & V \\
\hline 22248 & $\mathrm{R} 13$ & Uncharacterized protein & TAT & $\mathrm{T}$ & 83.7 & G & 16.3 & Y & $*$ \\
\hline 28580 & L18 & $\begin{array}{l}\text { Putative sel1-like repeat- } \\
\text { containing protein }\end{array}$ & $\mathbf{A} T$ & A & 76.9 & $\mathrm{~T}$ & 23.1 & । & $\mathrm{F}$ \\
\hline 47300 & L37 & $\begin{array}{l}\text { Putative KilA-N domain- } \\
\text { containing protein }\end{array}$ & ATC & A & 86.3 & G & 13.7 & । & v \\
\hline 54207 & $\llcorner 42$ & $\begin{array}{l}\text { Putative ankyrin repeat } \\
\text { protein }\end{array}$ & TTG & A & 63.8 & G & 36.2 & L & v \\
\hline 97232 & L77b & Uncharacterized protein & - & C & 88.3 & $\mathrm{~T}$ & 11.7 & A & V \\
\hline 166952 & R135 & $\begin{array}{l}\text { Putative GMC-type } \\
\text { oxidoreductase }\end{array}$ & GAT & $\mathrm{T}$ & 87.0 & C & 13.0 & D & D \\
\hline 322426 & L254 & $\begin{array}{l}\text { Heat shock protein } 70 \\
\text { homolog }\end{array}$ & ATT & $\mathrm{T}$ & 88.9 & A & 11.1 & । & । \\
\hline 328586 & R260 & DnaJ-like protein & TTC & $\mathrm{T}$ & 81.3 & G & 18.8 & $\mathrm{~F}$ & V \\
\hline 329434 & R261 & Uncharacterized protein & CAA & A & 85.7 & C & 14.3 & Q & $\mathrm{H}$ \\
\hline 399891 & R313 & $\begin{array}{l}\text { Ribonucleoside- } \\
\text { diphosphate reductase } \\
\text { large subunit }\end{array}$ & $\mathrm{A} \pi \mathrm{T}$ & A & 83.9 & C & 16.1 & I & $\mathrm{L}$ \\
\hline 440978 & R343 & Probable ribonuclease 3 & TGG & $\mathrm{T}$ & 89.9 & A & 10.1 & W & $\mathrm{R}$ \\
\hline 483113 & R367 & Uncharacterized protein & $\mathrm{AAA}$ & A & 86.2 & $\mathrm{~T}$ & 13.8 & K & । \\
\hline 504876 & - & - & - & $\mathrm{T}$ & 88.0 & G & 12.0 & - & - \\
\hline 601715 & $\llcorner 454$ & Uncharacterized protein & ATC & $\mathrm{T}$ & 87.3 & C & 12.7 & I & $\mathrm{T}$ \\
\hline 649432 & $\llcorner 485$ & Uncharacterized protein & GAA & A & 88.9 & C & 11.1 & $E$ & D \\
\hline 655506 & L490 & Uncharacterized protein & $\mathrm{ACC}$ & G & 85.1 & $\mathrm{~T}$ & 14.9 & $\mathrm{~T}$ & । \\
\hline 734179 & R547 & Uncharacterized protein & $\mathrm{AAC}$ & A & 84.7 & C & 15.3 & $N$ & $\mathrm{H}$ \\
\hline 736530 & R549b & $\begin{array}{l}\text { Uncharacterized probable } \\
\text { non-coding RNA gene }\end{array}$ & - & $\mathrm{T}$ & 88.0 & C & 12.0 & - & - \\
\hline 787617 & L594 & Uncharacterized protein & $\mathrm{AAA}$ & A & 73.5 & C & 26.5 & K & $\mathrm{T}$ \\
\hline 918583 & R699 & Uncharacterized protein & AAA & A & 87.5 & C & 12.5 & K & N \\
\hline 939044 & R714 & Uncharacterized protein & $\mathrm{TTT}$ & $\mathrm{T}$ & 69.0 & G & 31.0 & $\mathrm{~F}$ & C \\
\hline 962204 & R735 & Uncharacterized protein & CAA & A & 82.3 & C & 17.7 & Q & $\mathrm{H}$ \\
\hline 1069573 & R822 & Uncharacterized protein & ATT & A & 89.2 & G & 10.8 & 1 & V \\
\hline 1170156 & R903 & $\begin{array}{l}\text { Putative ankyrin repeat } \\
\text { protein }\end{array}$ & $\mathrm{TTT}$ & $\mathrm{T}$ & 89.1 & G & 10.9 & $\mathrm{~F}$ & C \\
\hline
\end{tabular}

the exact boundaries of transcripts using two large transcriptome data sets: one from a previously published study of Mimivirus polyadenylated RNAs [5], the other from a SOLiD ${ }^{\mathrm{TM}}$ sequencing of total RNA. The latter was generated from nine barcoded transcriptome libraries constructed at various time during the entire Mimivirus infection cycle using $1 \mu \mathrm{g}$ of total RNA from Acanthamoeba castellanii cells, each with the SOLiD ${ }^{\mathrm{TM}}$ Whole Transcriptome Analysis kit, and pooled at equimolar concentrations. After emulsion PCR the monoclonal beads were loaded on one slide of a SOLiD ${ }^{\mathrm{TM}} 3$ Plus System and sequenced ( 50 base pairs) with the SOLiD ${ }^{\mathrm{TM}}$ Opti Fragment Library Sequencing chemistry. A total of 202,436,309 reads were generated and subsequently aligned to the Mimivirus genome using Bfast [6]. The two combined RNA-seq datasets allowed the unambiguous identification of the 5 ' end of 555 Mimivirus transcripts as well as the 3' end of 601 transcripts at single base-pair resolution

We completed the genome annotation by mapping previously identified transcription regulation signals (i.e. the palindromic transcription termination signal [13], the early expression promoter element [14] and the late expression promoter element [5]) using the previously described protocols [5]. The combination of the deep transcriptome data mentioned above with the location of the predicted regulatory elements led to a substantial update of the Mimivirus gene map. Appendix lists the 
new genes identified from previously overlooked transcripts, as well as the new genes resulting from the correction of phase-shifting sequencing errors. The Mimivirus gene number is now of 1018, among which 979 putatively encode proteins, 6 encode tRNAs and 33 correspond to non-coding RNA genes. All these annotations are now included in the new reference Mimivirus entry (RefSeq NC_014649).

\section{One more Mimivirus-encoded component of the transcription apparatus}

Mimivirus was already known to encode a large number (if not all) of the components of its transcription apparatus: the two largest RNA Polymerase II subunits (R501 and L244), and four smaller subunits: Rpb3/ Rpb11 (R470), Rpb5 (L235), Rpb6 (R209), Rpb7/E (L376). Mimivirus also possesses its own poly(A) polymerase (R341), and a series of transcription factors (L250, R339, R350, R429, R450, R559). Such a virallyencoded transcription system is required by the fact that
Mimivirus genes are transcribed within well-defined cytoplasmic virion factories, with little or no participation of the host transcription apparatus localized in the cell nucleus. In order to bootstrap the infectious cycle, the above Mimivirus genes follow a late expression pattern allowing their protein products to be incorporated in the mature virions [15]. It turned out that the inventory of Mimivirus transcription-associated gene was not yet complete. Deeper sequencing of the Mimivirusinfected cells total RNA revealed a transcriptional activity (classified as "late") in between genes L357 and R358 (Figure 2A). This location corresponds to a short ORF (now denoted R357b) spanning 73 residues that exhibited no significant databases similarity at the time of our original annotation [1]. However, analyzing this predicted amino-acid sequence now suggests that it is a divergent homologue of the subunit $\mathrm{N}$ of RNA polymerase II. Interestingly, the closest relative ( $30 \%$ identity) of this new Mimivirus protein is found (Figure 2B) within the recently published $730 \mathrm{~kb}$-genome of a giant virus

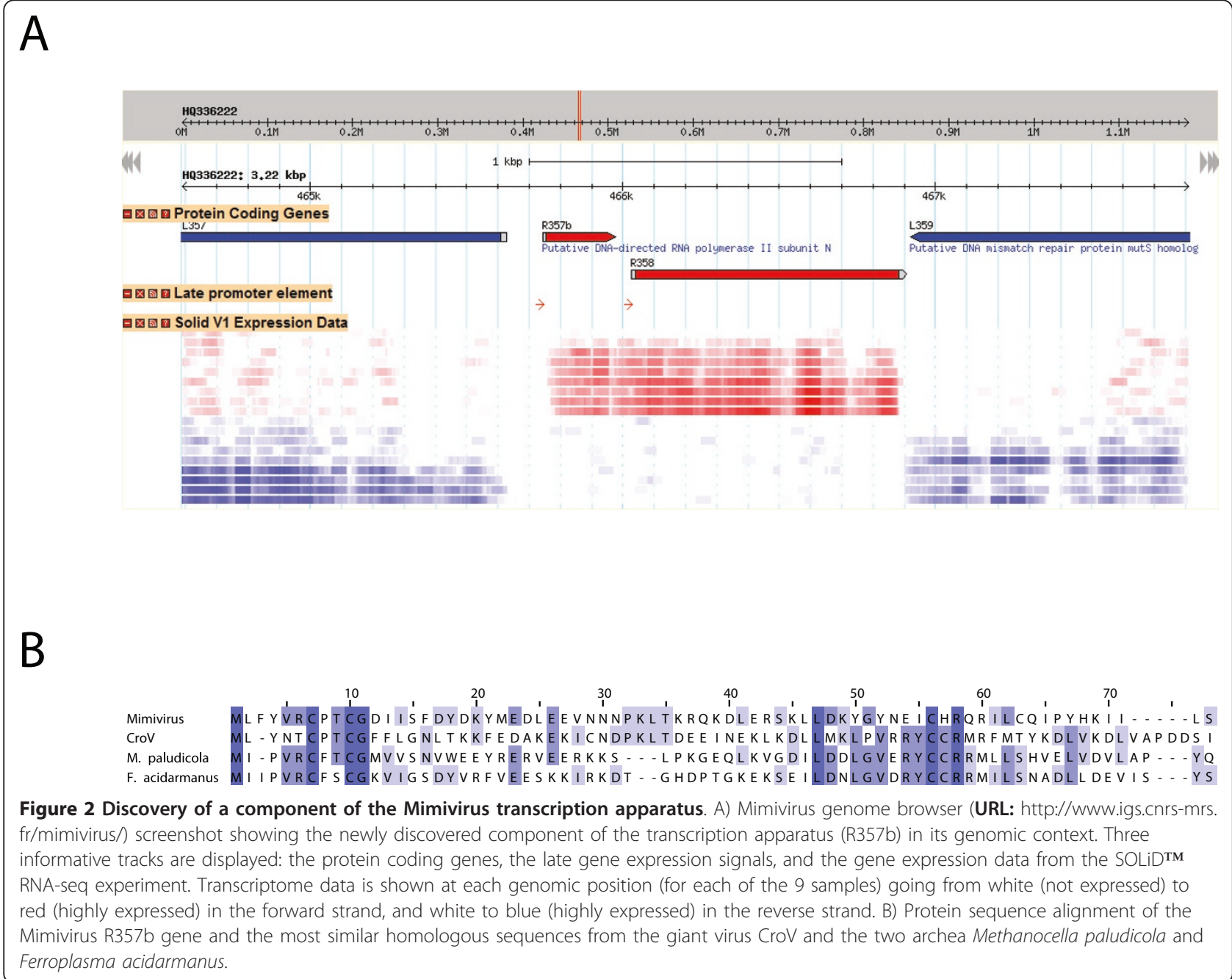


infecting the marine microflagellate Cafeteria roenbergensis [16]. These findings strongly suggest that R357b encodes a real protein, thus adding one more component to the already complex transcriptional machinery of Mimivirus. We hope that the accurate genome sequence and comprehensive transcript map now available for Mimivirus will make it a reference microorganism for future experimental and computational studies aiming at elucidating the physiology of giant DNA viruses.

\section{Appendix}

List of newly identified genes: R2b, L10c, R13b, R14, R14b, L34b, L37b, L38b, R61b, R61c, L61d, L66b, L78b, L83b, L88b, L98b, L173b, L174b, R191c, R213b, L309c, R328b, R357b, R365b, R437b, R437c, R449b, L482b, R485b, L487b, R538c, R559b, L565b, L577b, R607b, R661b, R676b, L681b, L684b, L692b, L696b, L769b, L794b, R878b, R884b, R908b, R910b, L911b, L911c.

List of genes generated from the fusion of previously identified ORFs: L91/L90, L93/L92, R391/R392, R527/ R528, R568/R569, R744/R745, R844/R845.

List of deleted or renamed genes: L14, L61b, R70, R847, R886.

\section{Acknowledgements}

We thank Kent Davidson for initiating this collaborative project with Life Technologies. This work was funded by the Centre National de la Recherche Scientifique and the Agence Nationale de la Recherche (ANR-BLAN08-0089). We acknowledge the use of the PACA-bioinfo IBISA platform.

\section{Author details}

${ }^{1}$ Structural \& genomic Information Laboratory (CNRS, UPR2589)

Mediterranean Institute of Microbiology, Aix-Marseille Université, 163 Avenue de Luminy, Case 934, FR-13288 Marseille, France. ' Life Technologies France SAS, 25 av. de la baltique, B.P. 96, 91943 Courtaboeuf Cedex 3, France.

\section{Authors' contributions}

$M L$ designed the study, conducted the data analysis and wrote the manuscript; SS participated in the data analysis and draft the manuscript; AR performed libraries construction and sequencing; CA participated in data analysis, produced the initial material and draft the manuscript; JMC designed the study and wrote the manuscript. All authors read and approved the final manuscript.

\section{Competing interests}

Life Technologies financed the chemical and sequencing for the project. AR is an employee of Life Technologies. There are no other financial and nonfinancial competing interests.

Received: 12 January 2011 Accepted: 4 March 2011 Published: 4 March 2011

\section{References}

1. Raoult D, Audic S, Robert C, Abergel C, Renesto P, Ogata H, La Scola B, Suzan M, Claverie JM: The 1.2-Megabase Genome Sequence of Mimivirus. Science 2004, 306:1344-1350.

2. Claverie JM, Abergel C: Mimivirus: the emerging paradox of quasiautonomous viruses. Trends in Genetics 2010, 26:431-437.

3. Forterre P: Giant viruses: conflicts in revisiting the virus concept. Intervirology 2010, 53:362-378
4. Raoult $D$, Forterre P: Redefining viruses: lessons from Mimivirus. Nat Rev Micro 2008, 6:315-319.

5. Legendre M, Audic S, Poirot O, Hingamp P, Seltzer V, Byrne D, Lartigue A, Lescot M, Bernadac A, Poulain J, Abergel C, Claverie JM: mRNA deep sequencing reveals 75 new genes and a complex transcriptional landscape in Mimivirus. Genome Res 2010, 20:664-674.

6. Homer N, Merriman B, Nelson SF: BFAST: An Alignment Tool for Large Scale Genome Resequencing. PLoS One 2009, 4(11):e7767.

7. Homer N, Nelson SF: Improved variant discovery through local realignment of short-read next-generation sequencing data using SRMA. Genome Biol 2010, 11:R99.

8. Li H, Handsaker B, Wysoker A, Fennell T, Ruan J, Homer N, Marth G, Abecasis G, Durbin R, 1000 Genome Project Data Processing Subgroup: The Sequence Alignment/Map format and SAMtools. Bioinformatics 2009, 25:2078-2079.

9. Koboldt DC, Chen K, Wylie T, Larson DE, McLellan MD, Mardis ER, Weinstock GM, Wilson RK, Ding L: VarScan: variant detection in massively parallel sequencing of individual and pooled samples. Bioinformatics 2009, 25:2283-2285.

10. Rocha EPC, Smith JM, Hurst LD, Holden MTG, Cooper JE, Smith NH, Feil EJ: Comparisons of $\mathrm{dN} / \mathrm{dS}$ are time dependent for closely related bacterial genomes. J. Theor. Biol 2006, 239:226-235.

11. Nei M, Gojobori T: Simple methods for estimating the numbers of synonymous and nonsynonymous nucleotide substitutions. Molecular Biology and Evolution 1986, 3:418-426.

12. Besemer J, Lomsadze A, Borodovsky M: GeneMarkS: a self-training method for prediction of gene starts in microbial genomes. Implications for finding sequence motifs in regulatory regions. Nucleic Acids Res 2001, 29:2607-2618.

13. Byrne D, Grzela R, Lartigue A, Audic S, Chenivesse S, Encinas S, Claverie JM, Abergel C: The polyadenylation site of Mimivirus transcripts obeys a stringent 'hairpin rule'. Genome Res 2009, 19:1233-1242.

14. Suhre K, Audic S, Claverie JM: Mimivirus gene promoters exhibit an unprecedented conservation among all eukaryotes. Proc Natl Acad SC USA 2005, 102:14689-14693.

15. Claverie JM, Abergel C, Ogata H: Mimivirus. Curr. Top. Microbiol. Immunol 2009, 328:89-121.

16. Fischer MG, Allen MJ, Wilson WH, Suttle CA: Giant virus with a remarkable complement of genes infects marine zooplankton. Proceedings of the National Academy of Sciences 2010, 107:19508-19513.

doi:10.1186/1743-422X-8-99

Cite this article as: Legendre et al:: Breaking the 1000-gene barrier for Mimivirus using ultra-deep genome and transcriptome sequencing. Virology Journal 2011 8:99.

\section{Submit your next manuscript to BioMed Central and take full advantage of:}

- Convenient online submission

- Thorough peer review

- No space constraints or color figure charges

- Immediate publication on acceptance

- Inclusion in PubMed, CAS, Scopus and Google Scholar

- Research which is freely available for redistribution 